\title{
GCU
}

Glasgow Caledonian

University

University for the Common Good

\section{Knee joint kinetics in response to multiple three-dimensional printed, customised foot orthoses for the treatment of medial compartment knee osteoarthritis}

Allan, Richard; Woodburn, James; Telfer, Scott; Abbott, Mandy; Steultjens, Martijn P.M.

Published in:

Proceedings of the Institution of Mechanical Engineers, Part $\mathrm{H}$ : Journal of Engineering in Medicine

DOI:

$10.1177 / 0954411917691318$

Publication date:

2017

Document Version

Author accepted manuscript

Link to publication in ResearchOnline

Citation for published version (Harvard):

Allan, R, Woodburn, J, Telfer, S, Abbott, M \& Steultjens, MPM 2017, 'Knee joint kinetics in response to multiple three-dimensional printed, customised foot orthoses for the treatment of medial compartment knee osteoarthritis', Proceedings of the Institution of Mechanical Engineers, Part H: Journal of Engineering in Medicine, vol. 231, no. 6, pp. 487-498. https://doi.org/10.1177/0954411917691318

\section{General rights}

Copyright and moral rights for the publications made accessible in the public portal are retained by the authors and/or other copyright owners and it is a condition of accessing publications that users recognise and abide by the legal requirements associated with these rights.

Take down policy

If you believe that this document breaches copyright please view our takedown policy at https://edshare.gcu.ac.uk/id/eprint/5179 for details of how to contact us. 


\section{Introduction}

2 Osteoarthritis $(\mathrm{OA})$ is one of the most prevalent musculoskeletal joint conditions throughout the world. In

3 the UK alone, it is estimated that more than 4.7 million people over the age of 45 years have sought

4 treatment from their general practitioner for knee osteoarthritis (1). As a weight-bearing joint the knee is

5 highly susceptible to OA, with the medial compartment of the knee joint more commonly affected. An

6 increased incidence of medial compartment knee OA (mKOA) has been attributed to the combination of

7 greater varus alignment (2) and the higher percentage of overall joint load being transmitted across the

8 medial compartment compared to the lateral compartment (approximately 70:30) (3).

9 Direct measurement of knee joint load is complex, with most in vivo contact loading studies restricted to

10 case studies, conducted using instrumented prostheses following knee replacement surgery (4-8). For

11 non-invasive studies, the knee adduction moment (KAM) is routinely adopted as a surrogate measure

12 whereby it is used to infer the dynamic load placed on the compartments of the knee $(3,9,10)$. This

13 external moment is mainly determined by the ground reaction force vector and its lever arm to the centre

14 of the knee joint. Using this measure, increased KAMs reflect greater medial compartment loading.

15 Foot orthoses (FOs) incorporating lateral wedges are routinely issued for individuals with mKOA. These

16 are intended to assist in the control and management of the disease by redistributing the total knee joint

17 load across the joint during weight bearing tasks, alleviating load on the affected medial compartment.

18 They function by causing an increased valgus moment at the ankle which causes a lateral shift of the

19 centre of pressure at the foot. This lateral shift causes the lever arm length of the ground reaction force vector relative to the knee joint origin to reduce, resulting in the theoretical reduction in the KAM.

21 The use of lateral wedged FOs has been shown to reduce the peak KAM by approximately $4-12 \%$ in

22 KOA cohorts $(11,12)$. However, there is growing evidence that the biomechanical response to orthotic intervention is heterogeneous and can, in some individuals, in fact elevate the KAM. Indeed it has been 
24 estimated that $13-33 \%$ of people with mKOA demonstrate a negative response to lateral wedged insoles, 25 despite beneficial effects reported at group level (12-16).

26 The majority of RCTs that have applied FO interventions for mKOA have generally focused on the 27 application of a single intervention device and compared it to a control condition, which varied between 28 studies $(14,15,17,18)$. It should however be considered that the requirements for a beneficial biomechanical response are likely to be more complex than a straightforward one-size-fits-all 30 intervention. It may be that different design characteristics will be effective in some individuals and not others, especially when the heterogeneity of the OA population is taken into consideration.

32 Advances in 3D printing technologies have resulted in the expansion of these techniques into the orthotic 33 environment (19-22) with numerous companies currently offering 3D printed FOs including Peacocks 34 Medical Group $\left(\right.$ a and SOLS Systems ${ }^{(}$. Studies which have adopted the combination of 3D surface 35 scanning, computer-aided design and computer-aided manufacturing (CAD/CAM) have produced custom 36 FOs of equivalent quality to traditional methods with improved reproducibility and design standardisation 37 (23). The application of these methods serves as a useful alternative to standard methods as it allows the creation of multiple personalised FOs facilitating small scale orthotic production for research. The ability to optimise orthotic design is specifically relevant in the mKOA population given the high variability between responses previously reported. The aim of this study therefore was to evaluate the immediate

41 biomechanical effect, at both group level and individual level when two key design features are altered in personalised FOs: orthotic length and degree of lateral wedging. 


\section{Materials and methods}

\section{$44 \quad$ Study design}

45 This cross-sectional observational study was conducted in a human performance laboratory at Glasgow

46 Caledonian University from November of 2013 to February 2015. Participants completed all orthotic 47 conditions on the same day.

48

49

\section{Participants}

Approval was obtained from the Institutional Research Ethics Committee at Glasgow Caledonian University. The procedures followed were in accordance with the ethical standards of the aforementioned research committee and with the Helsinki Declaration of 1975, revised in 2000. 20 participants were enrolled in the study, 10 in the mKOA group and 10 in the control group. All participants provided informed, written consent upon enrolment.

A convenient sample of mKOA participants was recruited via email to staff members of departments within the university and their associated friends and family as well as a MSK rehabilitation research email address which targets the community. Inclusion criteria for the mKOA group were $\geq 50$ years of age and physician-confirmed unilateral or bilateral mKOA. Inclusion criteria for the control group were: $\geq 50$ years; no history of unilateral/bilateral KOA; and have no chronic/stable knee pain in the past 3 months. Exclusion criteria for both groups were: BMI $\geq 36 \mathrm{~kg} / \mathrm{m}^{2}$; history of lower limb, hip or spinal surgery within the past 6 months; any other joint pathology which causes knee pain; received corticosteroid or other injections to or around the knee in the past 6 months; current or past (within 4 week) use of oral corticosteroids; any medical condition that may affect walking; current use of wedge insole/custom-made orthotics; and an aggregate foot posture index score $(\mathrm{FPI})<-9$ or $9>(24)$. This was assessed by a UK Health and Care Professions Council registered podiatrist (MA). 
66 To design the FOs first weight-bearing 3D surface scans of both feet were taken with the foot in a relaxed

67 standing position using an Easy-Foot-Scan 3D scanner (Baltic Orthoservice UAB, Kaunas, Lithuania. The application of 3D scanners to measure characteristics of foot shape have previously demonstrated reduced measurement variability compared to a traditional neutral suspension casting technique, irrespective of clinical experience (25). The generated 3-D model was converted into stl format and then exported into OrthoModel Pro 2013 computer aided design (CAD) Software (Delcam Plc, Birmingham, $\underline{\mathrm{UK} \text { ) to undergo the FO design steps. One CAD user with low level prior experience to CAD software and }}$ of biomechanical background (RA) was responsible for all stages of the design and manufacturing process. The user however had received formal training in its use prior to study commencement from a CAD expert (ST), who was in regular user of the OrthoModel software, designing 2 or 3 pairs of FOs per week over the previous $2 / 3$ years.

In the software, all FOs were designed using the "standard orthosis from scan" mode. This mode used the identification of specific anthropometric measurements of the foot model obtained from the foot scans to design the FO. These measurements included; forefoot width (mm), rearfoot width (mm), orthotic length $(\mathrm{mm})$ and medial arch height $(\mathrm{mm})$. Forefoot width was determined by the locations of the centre of the $\underline{\text { 1st and 5th metatarsal heads, rearfoot width based on the medial and lateral aspect of the heel at its widest }}$ point and the medial longitudinal arch height was determined by selecting the most proximal point of the arch relative to the plantar surface.

The implementation of these dimensions provided the basis for the model which could then be altered as such based on key design characteristics of degree of wedging and FO length. In the software, degree of wedging was set at extrinsic, lateral (valgus) resulting in alterations to the wedging of the surface in 
88 both to give the required design. FO length was adjusted in the software with finer adjustments being 89 made based on individual foot shape. All FOs had a set default thickness of $3.5 \mathrm{~mm}$ with a solid heel 90 component section. This was selected in accordance with routinely applied and generally accepted insole 91 thickness measurements.

92 In total eight variations to the neutral design FO were produced and manufactured for the most 93 symptomatic side in the mKOA group, as measured by a VAS scale for pain; or randomly chosen for the 94 healthy group. Variations under investigation included both a $3 / 4$ length and a full length FO with the 95 following degrees of wedging; $0^{\circ}$ 'neutral', $5^{\circ}$ rearfoot lateral wedging, $10^{\circ}$ rearfoot lateral wedging and 96 combination of $5^{\circ}$ forefoot and $10^{\circ}$ rearfoot lateral wedging. The non-test leg received a $0^{\circ}$ 'neutral' 97 posted FO of equivalent length during each test condition to remove any chance of altered gait patterns from differences in FO length. The FO design process took approximately 1.5-2 hours for all eight variations per participant. The fabrication time for the eight variations ( 10 insoles per participant; one set of neutral full length, one set of three-quarter full length and the six variations of the assigned test leg) was approximately $70-120$ hours, depending on participants shoe size.

Fused Deposition Modelling (FDM)

All FOs were manufactured via a Fused Deposition Modelling (FDM) approach using a desktop 3D printing system ( $3 \mathrm{~d}$ Touch; Bits from Bytes, Clevedon, UK). FDM is a method of additive manufacturing (AM) first patented and trademarked by Stratasys Inc. which involves building a 3D object layer-bylayer. Also commonly referred to as plastic jet printing (PJP) and fused filament fabrication (FFF), recently the method has become open sourced resulting in a more consumer driven application and increased number of marketed products. 
109 The 3D printing system used was a commercially available 3D printer and although its application is not

110 specific to FO manufacturing, it had previously been used in similar published studies by the research 111 group, allowing manufacturing to be performed in-house $(23,26)$. FOs were manufactured in a soft

112 polylactide (PLA) thermoplastic (www.orbi-tech.de: density- $>1.35 \mathrm{~g} / \mathrm{cm} 3$, tensile strength- $\sim 16 \mathrm{MPa}$, 113 strain at yield- $\sim 290 \%$, e-modulus- $\sim 380 \mathrm{MPa}$, shore hardness- 92A). This semi-rigid thermoplastic 114 polymer was selected as the material of choice based on previously published studies by the research 115 group $(23,26)$.

116 Axon 2 software (Bits from Bytes, Clevedon, UK) was used to prepare the FOs for printing. The software

117 functions by mathematically slicing the FO into layers and creating the toolpaths for each layer which the $1183 \mathrm{D}$ printer follows. Build settings used to print the FOs involved; a layer height of $0.25 \mathrm{~mm}$, fill density of $11952 \%$ and a printing temperature of $195^{\circ} \mathrm{C}$ with the inclusion of a printed raft and support material.

120 The FDM process of the 3D printing system functions by feeding the thermoplastic material at a set feed rate $(16 \mathrm{~mm} / \mathrm{s})$ through a temperature controlled nozzle head. Once in contact with the heating element inside the nozzle, the solid thermoplastic filament is heated towards its melting temperature, altering its structure into a molten, semi-liquid state. The nozzle travels in the $\mathrm{X}$ and $\mathrm{Y}$ directions and extrudes the molten thermoplastic material at a set flow rate (20 RPM) according to the toolpath for the layer, creating a cross sectional 2D layer on the build platform. Once complete, the build platform is lowered by a set height $(0.25 \mathrm{~mm})$ and the next layer is printed based on the next cross sectional layer. During this process, the two layers are bonded together through thermal fusion and then solidify together as the layers cool down. This process is repeated for each of the toolpath layers until the FO is complete. Once printed, support structures and rafts were manually removed and each FO was hand finished using sandpaper to ensure a sufficient surface quality suitable for wear during biomechanical evaluation. 


\section{Measurements}

133 Participants were tested in their own footwear to replicate their normal daily wear and comfort levels. A

134 four segment unilateral model was created for the test leg using a modified version of the Cleveland

135 Clinic marker set. This included markers placed bilaterally on the anterior and posterior superior iliac

136 spine and greater trochanters. Additionally, for the test leg, markers were placed on the lateral femoral

137 condyle, lateral malleolus, and on the shoe itself, over the posterior calcaneus, $1^{\text {st }}$ metatarsal head and the

$1385^{\text {th }}$ metatarsal head. To track the thigh and shank segments, shell-mounted clusters of four tracking

139 markers were placed on the lateral aspects of these segments. During the initial static standing trial

140 additional markers were placed on the medial femoral condyle and medial malleolus to determine relative

141 positioning of joint centres and were removed for dynamic trials.

142 For trials, a 14 camera motion capture system (Qualisys AB, Gothenburg, Sweden) operating at a 143 frequency of $120 \mathrm{~Hz}$ was used to capture the retroreflective markers. Simultaneously, a force plate 144 (9286B; Kistler Winterthur, Switzerland) embedded into the walkway was used to measure the ground 145 reaction forces at $2400 \mathrm{~Hz}$. These data capturing methods are standard practice in research investigating 146 the biomechanics of human movement.

147 After an initial FO fitting session and accommodation period of approximately one week, participants 148 returned to the laboratory for the main evaluation. A static trial was recorded with the participant standing 149 in the shod condition, and then anatomical markers were removed prior to collection of dynamic trials. 150 Walking trials were measured for the shod condition followed by eight FO conditions. Testing order was 151 randomised for each participant to avoid order effects and participants were blinded to the condition 152 during testing.

153 Participants were given time to acclimatise to each FO until a consistent gait pattern was observed. They 154 were then asked to walk along the walkway until a total of 7 successful force plate strikes with the test leg 
155

were recorded. Walking speed was standardised to within $\pm 10 \%$ of their self-selected walking speed during the shod test using photoelectric timing gates (Brower timing system, Draper, Utah, USA). A rest period was included between FO conditions to reduce potential effects of fatigue.

Knee joint moments were calculated from inverse dynamic analysis using Visual 3-D software (C-motion Inc., Germantown, MD). Variables associated with knee joint loading were identified and analysis was limited to these. These included; peak knee adduction moment during the $1^{\text {st }}$ half of stance phase (1KAM); peak knee adduction moment during the $2^{\text {nd }}$ half of stance phase (2KAM); knee flexion moment during the $1^{\text {st }}$ half of stance phase (1KFM); and the knee adduction moment impulse (KAMI) i.e. integral of the total KAM. Kinetic variables were anatomically referenced to the proximal segment. All variables of interest were normalised by dividing by body weight multiplied by height and then expressed as a percentage (For $1 \mathrm{KAM}, 2 \mathrm{KAM}$ and $1 \mathrm{KFM}$ this was $\mathrm{Nm} / \%$ body weight $\mathrm{x}$ height; for KAMI this was $\mathrm{Nms}^{-1} / \%$ body weight $\mathrm{x}$ height. This normalisation approach allowed for the effects of height and bodyweight to be considered-factors which significantly influence joint kinetics (27). The mean of the final 5 successful walking trials from each test condition with complete marker tracking was used in the analysis. Marker trajectories and GRF data were low passed filtered with a $4^{\text {th }}$ order Butterworth filter at 6 $\mathrm{Hz}$ and $25 \mathrm{~Hz}$, respectively.

\section{Statistical Analysis}

Statistical analyses were performed with SPSS (Norusis/SPSS, Chicago, IL) using $\alpha$ level of 0.05. Data were checked for normality, through Shapiro-Wilks tests, prior to analysis. All kinetic variables used in the analysis indicated normally distributed results. For analysis, all variables were defined relative to the shod condition, considered the baseline for the study and evaluated using a 3-factor, repeated-measures ANOVA to determine the main effect for group, length, wedging type and any interaction effects. 


\section{Results}

179 Demographic characteristics of study cohorts are presented in table 1 . The mKOA group was significantly 180 older and had a higher BMI than the healthy control group.

\section{INSERT TABLE 1}

182

Mean 1KAM, 2KAM, 1KFM and KAM Impulse values for each condition and group are presented in table 2.

\section{INSERT TABLE 2}

185

ANOVA results on all test variables are presented in table 3. Variable definitions include main effects of: orthotic length (three-quarter length/full length); group, (mKOA/control group); and wedging $\left(0^{\circ}\right.$ 'neutral', $5^{\circ}$ rearfoot wedging; $10^{\circ}$ rearfoot wedging and a combination of $5^{\circ}$ forefoot $10^{\circ}$ rearfoot wedging). Interaction effects between these variables are also provided.

\section{INSERT TABLE 3}

\section{IKAM}

Significant main effects were found for orthotic length in 1KAM ( $p=0.038)$. At the group level both FO lengths provided mean overall reductions in 1KAM compared to shod. This corresponded to a mean $\pm \mathrm{SD}$ percentage reduction in peak knee adduction moment in the 1 st half of stance of $1.1 \% \pm 12.3$ for the three-quarter length FOs and 2.8\% \pm 12.4 for the full lengths FOs.

Wedging condition was also found to be statistically significant for $1 \mathrm{KAM}(\mathrm{p}<0.001)$. With the exception of the neutrally posted FOs $(2 \% \pm 11.3$ increase $) 1 \mathrm{KAM}$ was reduced for all wedging conditions. This 
198 the $5^{\circ}$ rearfoot; $10^{\circ}$ rearfoot and combined $5^{\circ}$ forefoot $/ 10^{\circ}$ rearfoot wedging conditions respectively.

199 No significant interaction effects were found between the length of orthotic or level of wedging.

200 Furthermore no significant difference existed between the mKOA and healthy group

202 Significant main effects were found for orthotic length in $2 \mathrm{KAM}(\mathrm{p}=0.018)$. At the group level both FO 203 lengths provided a mean overall increase in 2KAM compared to the shod condition. This increase corresponded to a mean $\pm \mathrm{SD}$ percentage increase in $2 \mathrm{KAM}$ of $6.5 \% \pm 16.9$ for the three-quarter length FOs and $4.1 \% \pm 19.1$ for full length FOs.

206 An interaction effect was also found between FO length and group $(p=0.028)$. For the mKOA group 207 these differences corresponded to mean \pm SD percentage changes of $2.9 \% \pm 16.9$ and $2.7 \% \pm 19.1$ for the 208 three-quarter length and full length FOs respectively. The healthy group showed greater increases in 2KAM corresponding to mean \pm SD percentage changes of $10.2 \% \pm 16.9$ and $5.5 \% \pm 19.1$ for the threequarter length and full length FOs respectively.

211 Significant main effects were found for wedging for 2KAM $(p<0.0001)$. Irrespective of the orthotic 212 length, FOs had a somewhat negative effect on $2 \mathrm{KAM}$, corresponding to mean \pm SD percentage 213 increases in peak $2 \mathrm{KAM}$ of $9.5 \% \pm 12.9,5.8 \% \pm 12.5$ and $6.1 \% \pm 15.6$ for the neutral, $5^{\circ}$ rearfoot; $10^{\circ}$ 214 rearfoot wedging conditions respectively. No significant differences were found between OA and the 215 healthy groups. Furthermore, significant differences existed between the combined $5^{\circ}$ forefoot and $10^{\circ}$ rearfoot FO, considered the most biomechanically aggressive FO and all other wedging conditions. For this condition when compared to other wedging conditions there was a reduction of $9.6 \%, 5.9 \%$ and $6.6 \%$ 
218 when compared to the neutral, $5^{\circ}$ rearfoot; $10^{\circ}$ rearfoot wedging conditions respectively. However 219 compared to the shod condition it only produced a minimal 2KAM reduction of $0.1 \%$ (13.4).

220 Other significant interaction effects were found between orthotic length and wedging condition for $2212 \mathrm{KAM}(\mathrm{p}=0.002)$. For the three-quarter length FOs alterations to wedging corresponded to mean $\pm \mathrm{SD}$

222 percentage changes of $9.1 \% \pm 10.1,6.6 \% \pm 9.5,5.9 \% \pm 10.6$ and $4.5 \% \pm 9.6$ for the neutral, $5^{\circ}$ rearfoot, $22310^{\circ}$ rearfoot and combined $5^{\circ}$ forefoot $/ 10^{\circ}$ rearfoot wedging conditions respectively. Full length FOs 224 demonstrated a similar dose response with the exception of combined $5^{\circ}$ forefoot $/ 10^{\circ}$ rearfoot wedging 225 condition, corresponding to mean \pm SD percentage changes of $9.9 \% \pm 9.2,5 \% \pm 10.3,6.3 \% \pm 12.6$ and $2264.8 \% \pm 12.3$ for the neutral, $5^{\circ}$ rearfoot, $10^{\circ}$ rearfoot and combined $5^{\circ}$ forefoot $/ 10^{\circ}$ rearfoot wedging 227 conditions respectively. No significant differences were found between mKOA and the healthy group in 228 relation to $2 \mathrm{KAM}$.

\section{$229 \quad 1 K F M$}

230 For 1KFM, no significant main effects or any interaction effects were found. Although no statistically significant findings were evident $(\mathrm{p}=0.109)$ between the groups the mKOA group demonstrated a mean $( \pm \mathrm{SD}) 1 \mathrm{KFM}$ increase of $11.4 \% \pm 26.6$ compared to the healthy group, $4.3 \% \pm 26.6$.

\section{KAM Impulse}

234 Significant main effects were found for orthotic length in KAM Impulse $(\mathrm{p}=0.022)$. Irrespective of the group, the FO length provided different responses in terms of the KAM Impulse compared to the shod condition. This corresponded to a mean \pm SD KAMI percentage change of $2.1 \% \pm 16.8$ for three-quarter length FOs and $0.4 \% \pm 16.1$ for full length FOs. 
238 Significant interaction effects were found between orthotic length and group $(\mathrm{p}=0.036)$. For the mKOA 239 group this corresponded to a mean \pm SD KAMI percentage change of $-0.5 \% \pm 16.3$ and $-0.7 \% \pm 16.1$ for 240 the $3 / 4$ length and full length FOs respectively compared to the healthy group who demonstrated an 241 increase in KAMI of $4.6 \% \pm 16.3$ and $1.5 \% \pm 16.1$ for the $3 / 4$ length and full length FOs respectively.

242 Significant main effects were found for wedging for KAM Impulse $(\mathrm{p}<0.0001)$. Irrespective of group the 243 effect of wedging condition corresponded to mean \pm SD percentage changes of $5.9 \% \pm, 0.9 \% \pm 11,0.9 \%$

$244 \pm 9$ and $-2.6 \% \pm 10$ for the neutral, $5^{\circ}$ rearfoot; $10^{\circ}$ rearfoot and combined $5^{\circ}$ forefoot $/ 10^{\circ}$ rearfoot posted 245 conditions respectively.

246 Although borderline the interaction between wedging and orthotic length was not significant $(\mathrm{p}=0.055)$.

247 For the $3 / 4$ length FOs alterations to wedging corresponded to mean \pm SD percentage changes of $3 \% \pm 13$, $2481 \% \pm 9$ and $0 \% \pm 9$ for the $5^{\circ}$ rearfoot; $10^{\circ}$ rearfoot and combined $5^{\circ}$ forefoot $/ 10^{\circ}$ rearfoot wedging 249 conditions respectively. The full length FO demonstrated a slightly different pattern corresponding to 250 mean \pm SD percentage changes of $2 \% \pm 9,10 \% \pm 2$ and $-6 \% \pm 10$ for the $5^{\circ}$ rearfoot; $10^{\circ}$ rearfoot and 251 combined $5^{\circ}$ forefoot $/ 10^{\circ}$ rearfoot wedging conditions respectively.

\section{Individual Response}

253 The variable magnitude of response to orthotic changes across the biomechanical outcome measures is 254 evident when the high standard deviations and confidence intervals are considered. The variability in 255 biomechanical response was present in both groups.

\section{INSERT FIGURE 2}


260 Negative and positive responses to FOs were assessed in relation whether the percentage 261 increase/decrease was greater/less than the reported standard error of the mean (SEM) for each variable. 262 For 1KAM, 22/80 (27.5\%) of the assessments, incorporating the various wedging conditions for the 263 mKOA group, resulted in a negative biomechanical response over the SEM. The healthy group had an 264 incidence of 22/80 (27.5\%) negative responses. A positive 1KAM response above SEM was found in $26544 / 80(55 \%)$ for both mKOA and healthy groups. For the 2KAM, 41/80 (51.3\%) of assessments for the 266 mKOA group caused an inverse biomechanical response over the SEM. This compared to $58 / 80(72.3 \%)$ 267 negative responses for healthy group. A positive 2KAM response above SEM was found in 25/80 $268(31.3 \%)$ and 15/80 (18.8\%) for mKOA and healthy groups respectively. For KAMI, $29 / 80(36.3 \%)$ of the 269 assessments for the mKOA group demonstrated an inverse biomechanical effect over the SEM. This 270 compared to $42 / 80(52.3 \%)$ for the healthy group. In relation to a positive KAMI response, a reduction 271 below the SEM was found in $34 / 80(42.5 \%)$ and $25 / 80$ (31.3\%) for mKOA and healthy groups 272 respectively. For 1KFM, overall 50/80 (62.5\%) of the assessments demonstrated an increase in 1KFM in 273 response for the mKOA group over the SEM. The healthy group demonstrated increased 1 KFM in $43 / 80$ $274(53.8 \%)$. Whereas a reduction in 1KFM was reported in 13/80 (16.3\%) and 20/80 (25\%) for mKOA and 275 healthy groups respectively 


\section{Discussion}

278 The aim of this study was to investigate alterations in knee joint kinetics as a result of modifications in

279 design features of personalised FOs. Our findings suggest that when two key design features are altered 280 there is a significant heterogeneous mechanical response observed at the knee joint in both the OA and

281 healthy groups during walking. These results enhance our knowledge and understanding as to the 282 potential benefits of personalising FO interventions in order to provide a more positive immediate 283 biomechanical effect even when a heterogeneous biomechanical response exists between conditions for 284 individuals.

285 At the group level, the full length FOs caused a significant reduction in 1 KAM compared to the $3 / 4$ length 286 FOs indicating a better response to full length FOs by both study groups. These findings are similar to 287 those previously reported that wedging applied to the entire lateral border is more effective at reducing 288 1KAM than just at the heel (15).

289 Although significant effects of wedging were found for $2 \mathrm{KAM}$, the majority of conditions resulted in 290 elevated values, indicative of greater medial compartment loading. Overall the reduction in $1 \mathrm{KAM}$ did 291 not correspond to a reduction in $2 \mathrm{KAM}$ for most conditions. However there was a reduction in $2 \mathrm{KAM}$

292

293

294

295

296

297

298

299 for the $3 / 4$ length and the full length FOs which incorporated $5^{\circ}$ forefoot $/ 10^{\circ}$ rearfoot wedging. For these conditions mean $2 \mathrm{KAM}$ reduced by $0.5 \%$ and $4.7 \%$ respectively relative to shod in the mKOA and healthy group respectively. These reductions in 2KAM are similar to previously reported results(15,28). During the majority of the $2^{\text {nd }}$ period of stance the forefoot is the only component in contact with the ground. Biomechanically, it is hypothesised that wedging the entire forefoot section will further increase the rearfoot eversion moment, through an increase in its lever arm length across a longer period of the stance phase. Significant correlations have been reported between increased rearfoot eversion moments and reduced KAM moments (29). As such, increasing the overall period at which the FO is " 
300

301

302

303

304

305

306

307

308

309

310

311

312

313

314

315

316

317

318

319

320

321

322

biomechanically effective' for therefore makes sense and has been reported to be a key design feature to reduce KAM variables(15).

No significant main or interaction effects were found for 1KFM however it was evident that the lateral wedged orthotics provided a concomitant elevation of 1KFM across all FO conditions compared to the shod. The fact that no significant effects were found between FO conditions suggests that these increases may be attributable to the orthotic design itself. Walter and colleagues (6) suggested that a corresponding increase in KFM may attenuate any load reducing benefit of KAM reductions. In this study, our FOs caused a general elevation in $1 \mathrm{KFM}$ of $11.4 \%$ in the mKOA group, compared to $4.3 \%$ the healthy group (overall in $\sim 77.5 \%$ of all participant responses) therefore it remains unclear as to whether a reduction in medial contact force would have occurred even with the reported reductions in 1KAM and KAMI variables.

KAM impulse has been suggested as a more suitable measure to infer the loading of the medial compartment $(30,31)$ as it takes into consideration both the amplitude of the moment and the total period of stance. For the mKOA group, KAMI was reduced by all FOs which incorporated lateral wedging. The full length FO which incorporated $5^{\circ}$ forefoot $/ 10^{\circ}$ rearfoot wedging was found to be the most biomechanically effective FO. For this condition mean KAMI reduced by $4.9 \%$ relative to shod. Given the slightly longer walking time, it could be argued that the elevated 2KAM values reported could have translated into the KAMI however rearfoot wedged conditions, which reported increased 2KAM, demonstrated reductions in KAMI indicating that overall loading still reduced.

The reductions in KAMI in response to lateral wedged FOs are in line with those previously reported in the literature $(32,33)$. These findings reinforce the suggestion that FOs incorporating increased wedging across the full length of the lateral side will result in a greater reduction in cumulative load on the knee joint throughout the stance phase. However, these findings were found at the group level which 
323 demonstrated a high level of variability. It is important to note that other aspects such as individual

324 response to pain and tolerance to FO condition have to be taken into consideration when the severity of

325 lateral wedging is targeted.

326 In the present study, the variability between subjects in the knee joint loading characteristics of 1KAM,

327 2KAM and KAMI in response to the FO conditions appears greater to that reported in previous research.

328 Hinman et al (32) reported a negative response in $23 \%$ of participants with a $5^{\circ}$ lateral wedge. In the

329 mKOA group alone, across the variables linked to medial compartment loading a negative response was

330 evident and to a greater extent when FO conditions were grouped together, corresponding to an incidence

331 of $27.5 \%, 51.3 \%$ and $36.3 \%$ negative responses over the SEM for 1KAM, 2KAM and KAMI

332 respectively. Furthermore, for the $5^{\circ}$ lateral forefoot $/ 10^{\circ}$ lateral rearfoot wedged $\mathrm{FO}$, considered the most

333 biomechanically aggressive for reducing medial tibiofemoral compartment loading, participants in both

334 the mKOA group (2/10) and healthy group (3/10) experienced an increase in 1 KAM compared to shod

335 that was above the conditions SEM. One possible explanation to this variability is that the immediate

336 assessment of the multiple variations in FO design may have exaggerated these negative effects compared

337 to other studies which have tended to examine only one FO variation.

338 The capabilities of AM and FO design methods and their potential application in the orthotic sector have

339 received increased awareness in recent years. The FO design and manufacturing methods adopted in this

340 study offer a fast and effective alternative to the traditional orthotic manufacturing methods used in

341 standard care. For our study, the average time between participant's fitting sessions to final assessment

342 was approximately 25 days. Manufacturing time of the 8 remaining insoles only took approximately 56-

34396 hours print time (2 per day, approximately 4-5 days). Furthermore, the period between initial scan and

344 printing of the neutral FOs for the acclimatisation session was as short as 2 days, but was dependent on

345 total manufacturing volume. Traditional methods including plaster casting on the other hand often involve 
346 more cumbersome processes which require additional time, particularly during the manufacturing stage

347 (34). Future difficulties lie in the practical feasibility of integrating $3 \mathrm{D}$ design and manufacturing 348 technologies into the clinical environment in a way which will optimise patient care, drive down overhead 349 costs for health organisations and reduce the turnaround period between initial assessment and FO issue. 350 Furthermore the feasibility of a truly personalised device for each individual using this approach still 351 requires further assessment. The creation of a more streamlined approach to the process is required in 352 order to effectively tailor the personalised intervention to the point that it can be confidently predicted 353 that the intervention will provide a beneficial effect.

\section{Limitations \& Conclusion}

355 There are a number of limitations which warrant further discussion. Firstly, participants were instructed to 356 wear their own current trainer rather than a standardised shoe during testing. This may have contributed to 357 the variability in biomechanical response, based on the differences in mechanical characteristics of the 358 footwear, which could influence individual gait patterns. However, this approach was taken to reflect what participants would wear on a daily basis and was assumed not to disrupt their normal biomechanical gait pattern based on their routine use. Furthermore, as results are expressed relative to a shod test condition, this confounding factor is theoretically minimised in the results. We believe the methods applied in this study provide valid results whilst maintaining a pragmatic approach to an intervention study.

The cross sectional nature of the study focused on the immediate biomechanical response, with testing of each FO performed in a random order with little acclimatization period. It is unclear whether each of the conditions evaluated would have had a different effect if they were worn over an extended period of time.

367 Turpin and colleagues (35) reported that an extended period of wear would allow suitable acclimatization to an FO design to occur. However, the immediate biomechanical effect can provide a valuable indicator 
369 for longer term clinical outcomes. Hinman et al., (36) demonstrated a significant correlation between 370 immediate $1^{\text {st }}$ peak KAM reductions with lateral wedged FOs and improvements in WOMAC function 371 score at 3 month follow up, whereby individuals who demonstrated a greater reduction in the adduction 372 moment reported less physical disability

373 The OA population is known to be heterogeneous in nature. These findings of variability in response to 374 orthotic intervention in people with medial compartment knee OA further support the requirement to 375 develop a better understanding of responders/non-responders, perhaps based on other biomechanical and physical characteristics such as altered ankle joint motions (13).

377 To our knowledge, this study is the first to examine the immediate biomechanical response to multiple designs of personalised FOs in an mKOA group. These findings suggest that a blanket approach to orthotic prescription may not be an effective treatment plan irrespective of the perceived benefit at the group level. This may go some way to explain the negative findings from recent RCTs of this type of intervention and is a crucial consideration for the KOA population where orthotic prescription is routine practice. In theory under these methods there could be individuals with knee OA who are being prescribed FOs which cause increased KAMs possibly exacerbating their OA progression. A greater understanding is required as to which individuals respond to an orthotic intervention i.e. responder characteristics, as well as improving the ability to optimise the biomechanical response for each of these individuals. Difficulties lie in how we identify these "responsive" individuals early so that interventions can be implemented for long term benefit. Chapman and colleagues (13) reported that the biomechanics of the ankle/ subtalar joint complex plays an central role in KAM reduction and could perhaps predict those who are more likely to have a positive response. Furthermore Paterson and colleagues (37) recently reported a strong relationship between foot and knee pain in people with KOA, resulting in adverse effects on health outcomes and functionality. Future research requires the integration of in depth 
392 biomechanical analyses as well as additional clinical and risk factor assessments to identify and perhaps

393 predict FO responders. Increased involvement of the individual into this process may also be an important 394 consideration.

\section{Author contributions}

396 RA: collection and analysis of gait data, statistical analysis, and preparation of manuscript. JW: study 397 design and preparation of manuscript. ST: study design and preparation of manuscript. MA: study design, 398 data collection, and preparation of manuscript. MS: study design, preparation of manuscript and 399 interpretation of results.

\section{Role of funding source}

401 The authors declare that this research received no specific funding from anybody in the public, 402 commercial, or not-for-profit sectors.

\section{Conflict of interest}

404 The authors declare that they have no conflict of interest relating to the material presented in this article. 


\section{References}

406 1. Arthritis Research UK. Osteoarthritis in General Practice. Chesterfield: Arthritis

407 Research UK; 2013. 1-36 p.

408

2. Schmitt LC, Rudolph KS. Influences on knee movement strategies during

409 walking in persons with medial knee osteoarthritis. Arthritis Rheum. 2007 Aug

410 $15 ; 57(6): 1018-26$.

411

3. Schipplein OD, Andriacchi TP. Interaction between active and passive knee stabilizers during level walking. J Orthop Res. 1991 Jan;9(1):113-9.

4. D'Lima DD, Patil S, Steklov N, Slamin JE, Colwell CW. Tibial forces measured in vivo after total knee arthroplasty. J Arthroplasty. 2006 Feb;21(2):255-62.

5. Kutzner I, Heinlein B, Graichen F, Bender A, Rohlmann A, Halder A, et al. Loading of the knee joint during activities of daily living measured in vivo in five subjects. J Biomech. Elsevier; 2010 Aug 10;43(11):2164-73.

6. Walter JP, D’Lima DD, Colwell CW, Fregly BJ. Decreased knee adduction moment does not guarantee decreased medial contact force during gait. J Orthop Res. 2010 Oct;28(10):1348-54. external knee load and EMG measures accurate indicators of internal knee contact forces during gait? J Orthop Res. 2013 Jun;31(6):921-9. 
424 8. Zhao D, Banks SA, Mitchell KH, D’Lima DD, Colwell CW, Fregly BJ.

425 Correlation between the knee adduction torque and medical contact force for a 426 variety of gait patterns. J Orthop Res. 2007 Jun;25(6):789-97.

4279 . Foroughi N, Smith R, Vanwanseele B. The association of external knee adduction moment with biomechanical variables in osteoarthritis: a systematic review. Knee. Elsevier B.V.; 2009 Oct;16(5):303-9.

10. Baliunas a. J, Hurwitz DE, Ryals a. B, Karrar a., Case JP, Block J a., et al. Increased knee joint loads during walking are present in subjects with knee osteoarthritis. Osteoarthr Cartil. 2002 Jul;10(7):573-9.

11. Baker K, Goggins J, Xie H, Szumowski K, LaValley M, Hunter DJ, et al. A randomized crossover trial of a wedged insole for treatment of knee osteoarthritis. Arthritis Rheum. 2007;56(4):1198-203.

12. Kakihana W, Akai M, Nakazawa K, Takashima T, Naito K, Torii S. Effects of laterally wedged insoles on knee and subtalar joint moments. Arch Phys Med Rehabil. 2005 Jul;86(7):1465-71.

13. Chapman GJ, Parkes MJ, Forsythe L, Felson DT, Jones RK. Ankle motion influences the external knee adduction moment and may predict who will respond to lateral wedge insoles?: An ancillary analysis from the SILK trial. Osteoarthr Cartil. Elsevier Ltd; 2015 Mar 5;4-10. 
443 14. Bennell KL, Bowles K-A, Payne C, Cicuttini F, Williamson E, Forbes A, et al. 444 Lateral wedge insoles for medial knee osteoarthritis: 12 month randomised controlled trial. BMJ. 2011 May 18;342(may18 3):d2912.

15. Hinman RS, Bowles KA, Payne C, Bennell KL. Effect of length on laterallywedged insoles in knee osteoarthritis. Arthritis Rheum. 2008 Jan 15;59(1):144-7.

16. Erhart JC, Mündermann A, Elspas B, Giori NJ, Andriacchi TP. A variable-

17. Barrios JA, Butler RJ, Crenshaw JR, Royer TD, Davis IS. Mechanical effectiveness of lateral foot wedging in medial knee osteoarthritis after 1 year of wear. J Orthop Res. 2012 Oct 23;1-6.

18. Toda Y, Tsukimura N. Influence of concomitant heeled footwear when wearing a lateral wedged insole for medial compartment osteoarthritis of the knee. Osteoarthr Cartil. 2008 Feb;16(2):244-53.

19. Telfer S, Pallari J, Munguia J, Dalgarno K, McGeough M, Woodburn J. Embracing additive manufacture: implications for foot and ankle orthosis design. BMC Musculoskeletal Disorders. 2012.

20. Pallari JHP, Dalgarno KW, Woodburn J. Mass customization of foot orthoses for 
rheumatoid arthritis using selective laser sintering. IEEE Trans Biomed Eng. $2010 \mathrm{Jul} ; 57(7): 1750-6$.

21. Mavroidis C, Ranky RG, Sivak ML, Patritti BL, DiPisa J, Caddle A, et al. Patient specific ankle-foot orthoses using rapid prototyping. J Neuroeng Rehabil. BioMed Central Ltd; 2011 Jan;8(1):1.

22. Dombroski CE, Balsdon MER, Froats A. The use of a low cost $3 \mathrm{D}$ scanning and printing tool in the manufacture of custom-made foot orthoses: a preliminary study. BMC Res Notes. 2014 Jan;7(1):443.

23. Telfer S, Gibson KS, Hennessy K, Steultjens MP, Woodburn J. Computer-aided design of customized foot orthoses: Reproducibility and effect of method used to obtain foot shape. Arch Phys Med Rehabil. Elsevier Inc.; 2012;93(5):863-70.

24. Redmond AC, Crosbie J, Ouvrier R a. Development and validation of a novel rating system for scoring standing foot posture: The Foot Posture Index. Clin Biomech. 2006 Jan;21(1):89-98.

25. Carroll M, Annabell M-E, Rome K. Reliability of capturing foot parameters using digital scanning and the neutral suspension casting technique. J Foot Ankle Res. BioMed Central Ltd; 2011;4(1):9.

26. Telfer S, Abbott M, Steultjens M, Rafferty D, Woodburn J. Dose-response effects of customised foot orthoses on lower limb muscle activity and plantar 
pressures in pronated foot type. Gait Posture. Elsevier B.V.; 2013 Jul;38(3):4439.

27. Moisio KC, Sumner DR, Shott S, Hurwitz DE. Normalization of joint moments during gait: A comparison of two techniques. J Biomech. 2003 Apr;36(4):599_603.

28. Kerrigan DC, Lelas JL, Goggins J, Merriman GJ, Kaplan RJ, Felson DT. Effectiveness of a lateral-wedge insole on knee varus torque in patients with knee osteoarthritis. Arch Phys Med Rehabil. 2002 Jul;83(7):889-93.

29. Levinger P, Menz HB, Morrow AD, Bartlett JR, Feller J a, Bergman NR.

30. Kean CO, Hinman RS, Bowles KA, Cicuttini F, Davies-Tuck M, Bennell KL. Comparison of peak knee adduction moment and knee adduction moment impulse in distinguishing between severities of knee osteoarthritis. Clin Biomech. Elsevier Ltd; 2012 Jun;27(5):520-3.

31. Thorp LE, Sumner DR, Block J a., Moisio KC, Shott S, Wimmer M a. Knee joint loading differs in individuals with mild compared with moderate medial knee osteoarthritis. Arthritis Rheum. 2006 Dec;54(12):3842-9. 
500

501

502

503

504

505

506

507

508

509

510

511

512

513

514

515

516

517

518

32. Hinman RS, Bowles KA, Metcalf BB, Wrigley T V., Bennell KL. Lateral wedge insoles for medial knee osteoarthritis: effects on lower limb frontal plane biomechanics. Clin Biomech (Bristol, Avon). Elsevier Ltd; 2012 Jan;27(1):2733.

33. Jones RK, Zhang M, Laxton P, Findlow AH, Liu A. The biomechanical effects of a new design of lateral wedge insole on the knee and ankle during walking. Hum Mov Sci. Elsevier B.V.; 2013 Aug;32(4):596-604.

34. Payne C. Cost benefit comparison of plaster casts and optical scans of the foot for the manufacture of foot orthoses. Australas J Podiatr Med. 2007;41(2):29-31.

35. Turpin KM, De Vincenzo A, Apps AM, Cooney T, MacKenzie MD, Chang R, et al. Biomechanical and clinical outcomes with shock-absorbing insoles in patients with knee osteoarthritis: Immediate effects and changes after 1 month of wear. Arch Phys Med Rehabil. Elsevier Inc.; 2012 Mar;93(3):503-8.

36. Hinman RS, Payne C, Metcalf BR, Wrigley T V., Bennell KL. Lateral wedges in knee osteoarthritis: What are their immediate clinical and biomechanical effects and can these predict a three-month clinical outcome? Arthritis Care Res. 2008 Mar 15;59(3):408-15.

37. Paterson KL, Hinman RS, Hunter DJ, Wrigley T V., Bennell KL. Impact of Concurrent Foot Pain on Health and Functional Status in People with Knee 


\begin{tabular}{|c|c|c|c|c|}
\hline & \multicolumn{2}{|c|}{ mKOA Group $(n=10)$} & \multicolumn{2}{|c|}{ Healthy Group $(n=10)$} \\
\hline Subject characteristics & \multicolumn{2}{|c|}{ Mean (SD) } & \multicolumn{2}{|c|}{ Mean (SD) } \\
\hline Gender (F:M) & \multicolumn{2}{|l|}{$7: 3$} & \multicolumn{2}{|l|}{$7: 3$} \\
\hline Age (years) & \multicolumn{2}{|l|}{$63.3(8.0) \neq$} & \multicolumn{2}{|c|}{$55.3(4.0) \neq$} \\
\hline $\mathrm{BMI}\left(\mathrm{kg} / \mathrm{m}^{2}\right)$ & \multicolumn{2}{|c|}{$27.1(2.8) \neq$} & \multicolumn{2}{|c|}{$23.6(2.3) \neq$} \\
\hline $\begin{array}{l}\text { Foot Posture Index, } \\
\text { TL/NTL* }\end{array}$ & $2.6(2.7)$ & $2.2(2.7)$ & $2.4(1.6)$ & $2.7(1.7)$ \\
\hline $\begin{array}{l}\text { Predicted Radiographic } \\
\text { Alignment, TL/NTL* }\end{array}$ & $1.36(2.2)$ & $2.3(3.1)$ & $1.4(1.9)$ & $0.7(1.9)$ \\
\hline Walking Speed $\left(\mathrm{ms}^{-1}\right)$ & \multicolumn{2}{|l|}{$4.7(0.6)$} & \multicolumn{2}{|l|}{$4.2(0.9)$} \\
\hline
\end{tabular}

*Test Leg (TL) and Non Test Leg (NTL)

$\neq$ Significant differences between groups $(p \leq 0.05)$ 


\begin{tabular}{|c|c|c|c|c|c|c|c|c|c|c|c|c|c|c|c|c|}
\hline \multirow[b]{3}{*}{ Parameter } & \multicolumn{4}{|c|}{$3 / 4$ length, $0^{\circ}$ 'neutral' } & \multicolumn{4}{|c|}{$3 / 4$ length, $5^{\circ} \mathrm{RF}$ lateral wedging } & \multicolumn{4}{|c|}{$3 / 4$ length, $10^{\circ}$ RF lateral wedging } & \multicolumn{4}{|c|}{$3 / 4$ length, $5^{\circ} \mathrm{FF} / 10^{\circ} \mathrm{RF}$ lateral wedging } \\
\hline & \multicolumn{2}{|c|}{ mKOA } & \multicolumn{2}{|c|}{ Control } & \multicolumn{2}{|c|}{ mKOA } & \multicolumn{2}{|c|}{ Control } & \multicolumn{2}{|c|}{ mKOA } & \multicolumn{2}{|c|}{ Control } & \multicolumn{2}{|c|}{ mKOA } & \multicolumn{2}{|c|}{ Control } \\
\hline & Mean (SD) & $95 \% \mathrm{CI}$ & Mean (SD) & $95 \% \mathrm{CI}$ & Mean (SD) & $95 \% \mathrm{CI}$ & Mean (SD) & $95 \% \mathrm{CI}$ & Mean (SD) & $95 \% \mathrm{CI}$ & mean $\pm \mathrm{SD}$ & $95 \%$ CI & Mean (SD) & $95 \% \mathrm{CI}$ & Mean (SD) & $95 \% \mathrm{CI}$ \\
\hline $1 \mathrm{KAM}$ & $0.1(8.8)$ & $-5.8,5.9$ & $3.6(8.9)$ & $-2.2,9.5$ & $-1.7(8.1)$ & $-6.4,3$ & $-1.8(5.8)$ & $-6.5,2.9$ & $-4(8.1)$ & $-8.7,0.7$ & $-1.8(5.7)$ & $-6.4,2.9$ & $-2.6(6.4)$ & $-6.4,1.3$ & $-0.8(5.2)$ & $-4.6,3.1$ \\
\hline 2KAM & $6.9(10.3)$ & $2,13.6$ & $11.3(9.9)$ & $4.6,18$ & $1.5(10.1)$ & $-4.8,7.8$ & $11.7(8.8$ & $5.4,18$ & $3.7(11.1)$ & $-3.4,10.7$ & $8.2(10.1)$ & $1.2,15.3$ & $-0.5(5.1)$ & $-7,6$ & $9.4(12.8)$ & $2.9,15.9$ \\
\hline $1 \mathrm{KFM}$ & $7.9(9)$ & $8,14.9$ & $4.5(12)$ & $-2.5,11.6$ & $10.9(21.6)$ & $2,21.6$ & $1.7(7.5)$ & $-9,12.4$ & $17.3(12.4)$ & $9.7,24.9$ & $5.2(10.5)$ & $-2.4,12.9$ & $12.8(15.5)$ & $3.4,22.3$ & $6.2(12.8)$ & $-3.2,15.7$ \\
\hline \multirow[t]{3}{*}{ KAMI } & $4.2(9.4)$ & $-1.7,10 . .2$ & $6.8(8.5)$ & $0.8,12.7$ & $-2(10.9)$ & $-8.9,5$ & $4.2(9.9)$ & $-2.7,11.2$ & $-1.4(7.9)$ & $-7.2,4.3$ & $4(9.4)$ & $-1.8,9.7$ & $-2.9(5.8)$ & $-8.3,2.5$ & $3.6(9.9)$ & $-1.8,9$ \\
\hline & \multicolumn{4}{|c|}{ Full length, $0^{\circ}$ 'neutral' } & \multicolumn{4}{|c|}{ Full length, $5^{\circ} \mathrm{RF}$ lateral wedging } & \multicolumn{4}{|c|}{ Full length $10^{\circ} \mathrm{RF}$ lateral wedging } & \multicolumn{4}{|c|}{ Full length, $5^{\circ} \mathrm{FF} / 10^{\circ} \mathrm{RF}$ lateral wedging } \\
\hline & \multicolumn{2}{|c|}{ mKOA } & \multicolumn{2}{|c|}{ Control } & \multicolumn{2}{|c|}{ mKOA } & \multicolumn{2}{|c|}{ Control } & \multicolumn{2}{|c|}{ mKOA } & \multicolumn{2}{|c|}{ Control } & \multicolumn{2}{|c|}{ mKOA } & \multicolumn{2}{|c|}{ Control } \\
\hline Parameter & Mean (SD) & $95 \%$ CI & Mean (SD) & $95 \% \mathrm{CI}$ & Mean (SD) & $95 \% \mathrm{CI}$ & Mean (SD) & $95 \%$ CI & Mean (SD) & $95 \% \mathrm{CI}$ & mean $(\mathrm{SD})$ & $95 \% \mathrm{CI}$ & Mean (SD) & $95 \% \mathrm{CI}$ & Mean (SD) & $95 \% \mathrm{CI}$ \\
\hline $1 \mathrm{KAM}$ & $-0.4(5.9)$ & $-5.8,5$ & $4.5(9.8)$ & $-0.8,9.9$ & $-3.6(10)$ & $-9.2,2.1$ & $-2(6.7)$ & $-7.6,3.7$ & $-6.8(6.3)$ & $-10.8,5$ & $-3.4(5.6)$ & $-7.4,0.6$ & $-5.4(8.2)$ & $-10.5,-2.3$ & $-5.4(7.2)$ & $-10.6,-0.3$ \\
\hline $2 \mathrm{KAM}$ & $8.6(7.1)$ & $2.6,14.7$ & $11.1(10.8)$ & $5,17.2$ & $3.2(10.3)$ & $-3.7,10$ & $6.8(10.3)$ & $0,13.6$ & $3.6(11.4)$ & $-4.7,12$ & $8.9(13.7)$ & $0.5,17.3$ & $-4.7(10.2)$ & $-12.9,3.5$ & $-4.8(14.1)$ & $-13,3.4$ \\
\hline $1 \mathrm{KFM}$ & $10.1(11)$ & $2.8,17.4$ & $1.5(10.9)$ & $-5.8,8.8$ & $12.9(19.7)$ & $1.2,24.7$ & $5.5(15.4)$ & $-6.3,17.2$ & $8.6(15.2)$ & $-0.1,17.2$ & $6.3(10.3)$ & $-2.3,14.9$ & $10.7(20.6)$ & $0.1,21.4$ & $3.1(9.4)$ & $-7.5,13.8$ \\
\hline KAMI & $5.3(7.5)$ & $-0.5,11.2$ & $7.3(9.9)$ & $1.5,13.2$ & $-1.2(8.7)$ & $-7.1,4.8$ & $2.3(9.2)$ & $-3.6,8.3$ & $-2(7.5)$ & $-8.4,1.5$ & $2.4(11.4)$ & $-4,8.8$ & $-4.9(7.6)$ & $-11.4,1.5$ & $-4(11.5)$ & $-12.5,0.4$ \\
\hline
\end{tabular}



are highlighted in bold)

\begin{tabular}{|c|c|c|c|}
\hline Parameter & Effect & $\mathrm{F}$ & p-value \\
\hline \multirow[t]{6}{*}{ 1st Peak Knee Adduction Moment } & Length & 4.986 & 0.038 \\
\hline & Length $x$ Group & 0.161 & 0.693 \\
\hline & Wedging & 11.564 & $<0.0001$ \\
\hline & Wedging x Group & 1.094 & 0.360 \\
\hline & Length $\mathrm{x}$ Wedging & 1.391 & 0.255 \\
\hline & Length $\mathrm{x}$ Wedging $\mathrm{x}$ Group & 0.318 & 0.812 \\
\hline \multirow[t]{6}{*}{ 2nd Peak Knee Adduction Moment } & Length & 6.820 & .018 \\
\hline & Length x Group & 5.693 & .028 \\
\hline & Wedging & 14.865 & $<0.0001$ \\
\hline & Wedging x Group & 0.467 & 0.706 \\
\hline & Length $\mathrm{x}$ Wedging & 5.466 & 0.002 \\
\hline & Length $\mathrm{x}$ Wedging $\mathrm{x}$ Group & 1.440 & 0.241 \\
\hline \multirow[t]{6}{*}{ 1st Peak Knee Flexion Moment } & Length & 0.571 & 0.460 \\
\hline & Length x Group & 0.261 & .616 \\
\hline & Wedging & 0.800 & .499 \\
\hline & Wedging x Group & 0.097 & 0.961 \\
\hline & Length $\mathrm{x}$ Wedging & 0.519 & 0.671 \\
\hline & Length $\mathrm{x}$ Wedging $\mathrm{x}$ Group & 0.601 & 0.617 \\
\hline \multirow[t]{6}{*}{ Knee Adduction Moment Impulse } & Length & 6.280 & 0.022 \\
\hline & Length $x$ Group & 5.114 & 0.036 \\
\hline & Wedging & 19.709 & $<0.0001$ \\
\hline & Wedging $\mathrm{x}$ Group & 0.764 & 0.519 \\
\hline & Length x Wedging & 3.237 & 0.029 \\
\hline & Length $\mathrm{x}$ Wedging $\mathrm{x}$ Group & 1.008 & 0.396 \\
\hline
\end{tabular}


528 Figure 1. Picture of the 3D printing system used in the FDM process (3d Touch; Bits from 529 Bytes, Clevedon, UK)

530 Figure 2. Group and individual changes in the first peak knee adduction moment (1KAM)

531 for each FO condition, reported as the percentage change relative to shod condition.

532 Figure 3. Group and individual changes in the second peak knee adduction moment (2KAM)

533 for each FO condition, reported as the percentage change relative to shod condition.

534 Figure 4. Group and individual changes in the first peak knee flexion moment (1KFM) for 535 each FO condition, reported as the percentage change relative to shod condition.

536 Figure 5. Group and individual changes in the knee adduction moment impulse (KAMI) for 537 each FO condition, reported as the percentage change relative to shod condition. 


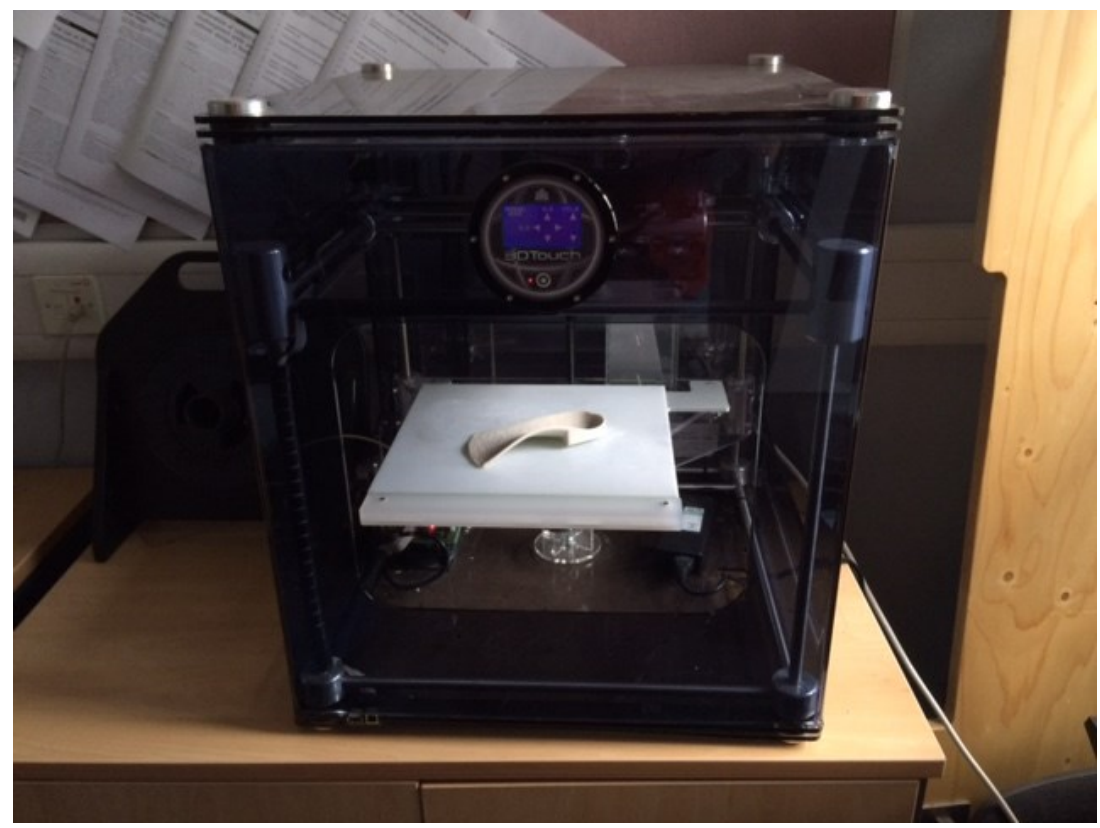

Figure 1

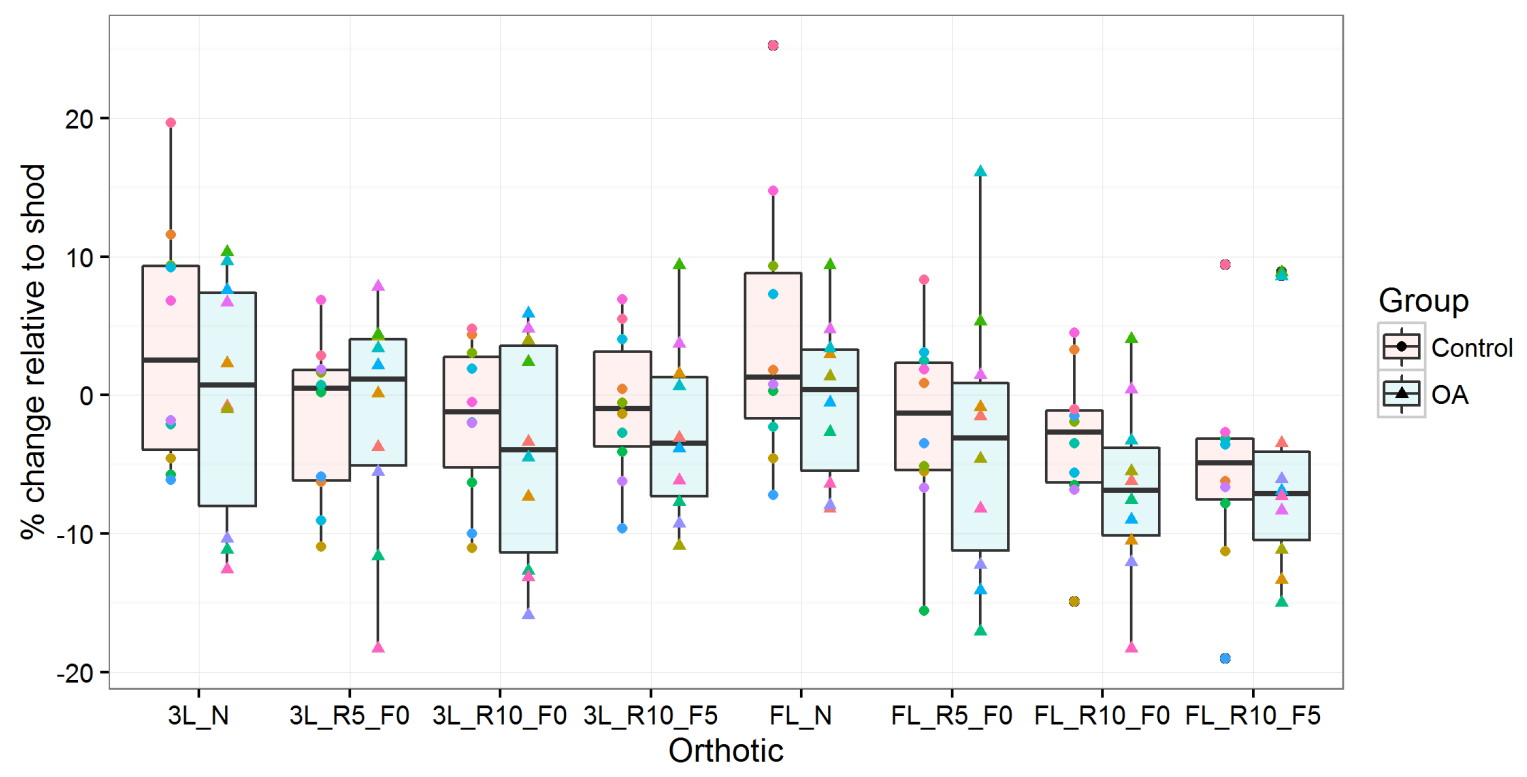

Figure 2 


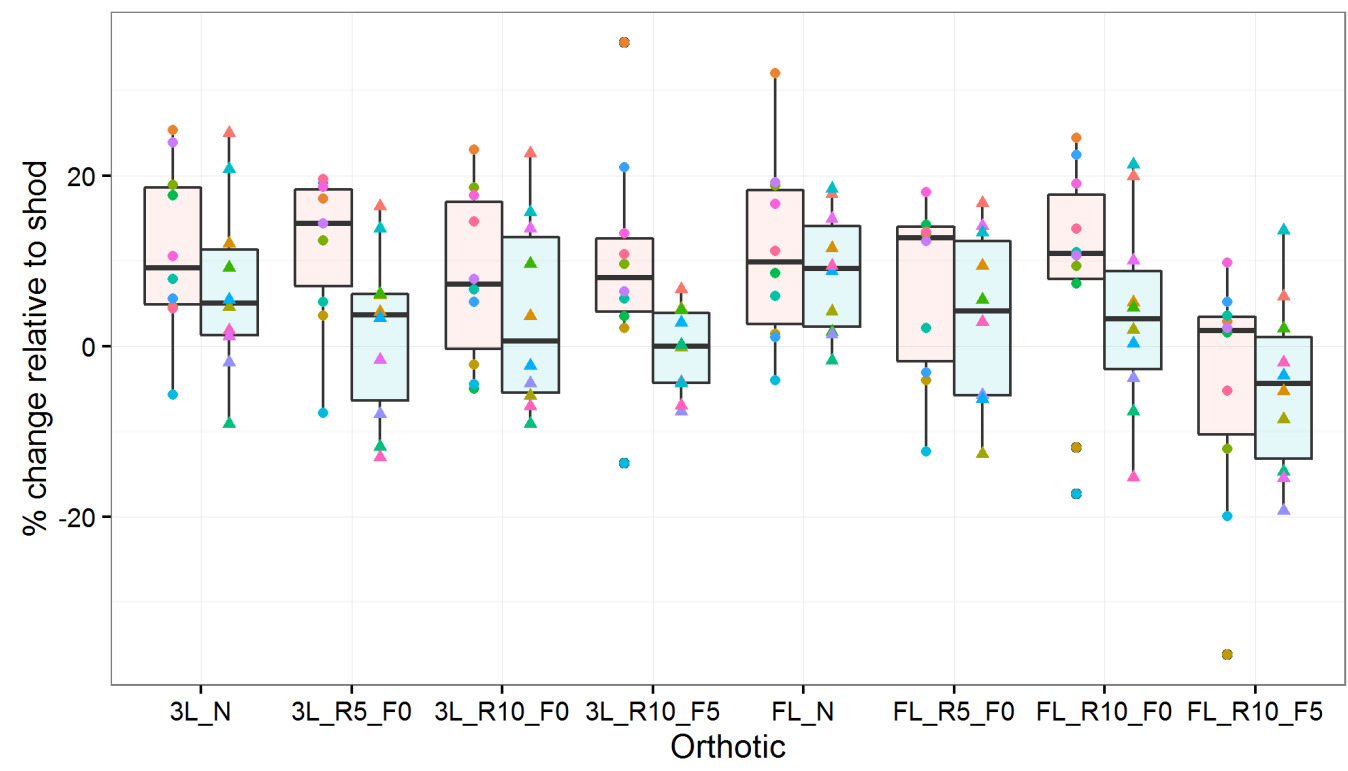

Group

E. Control

투 $O A$

Figure 3

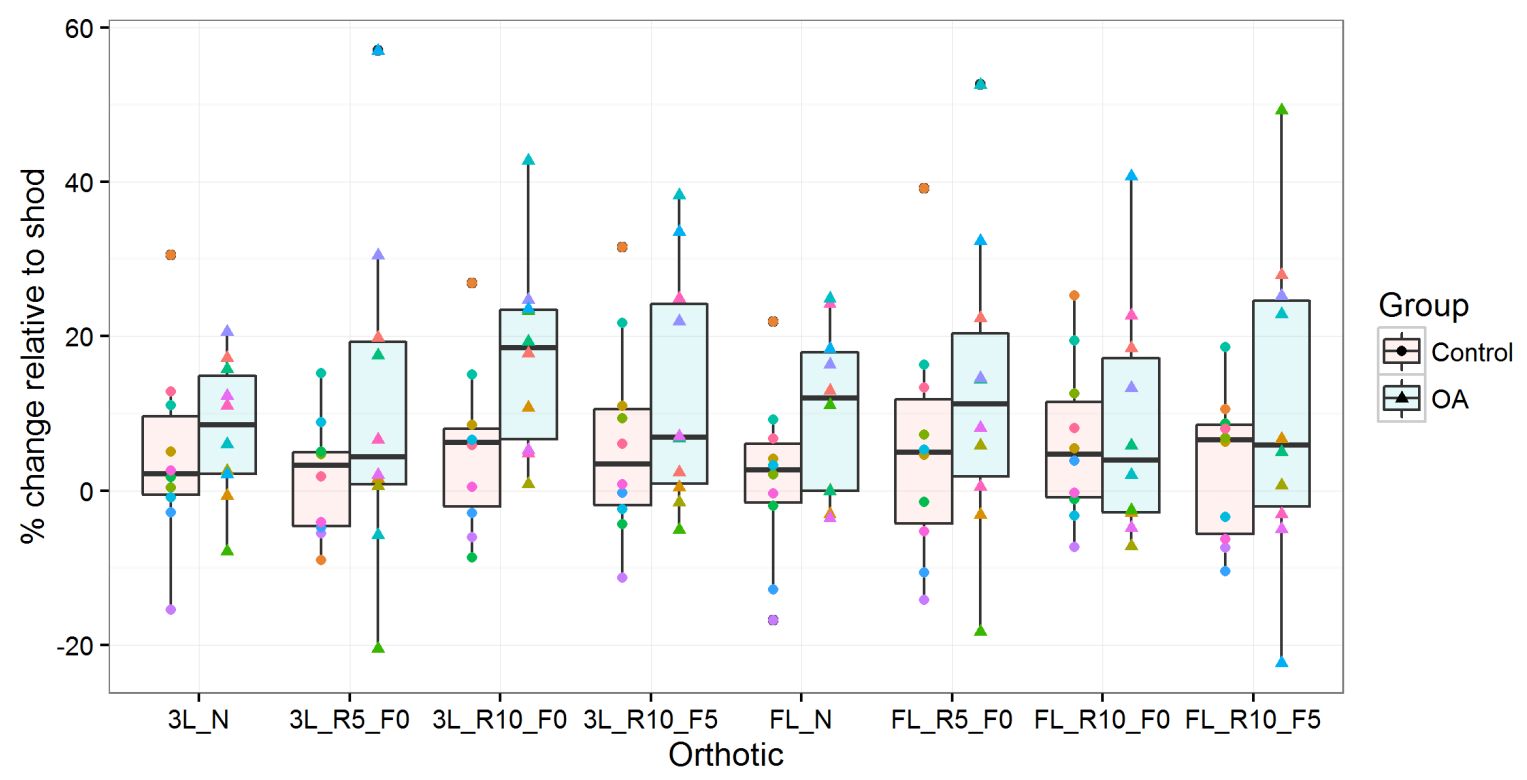

Figure 4 


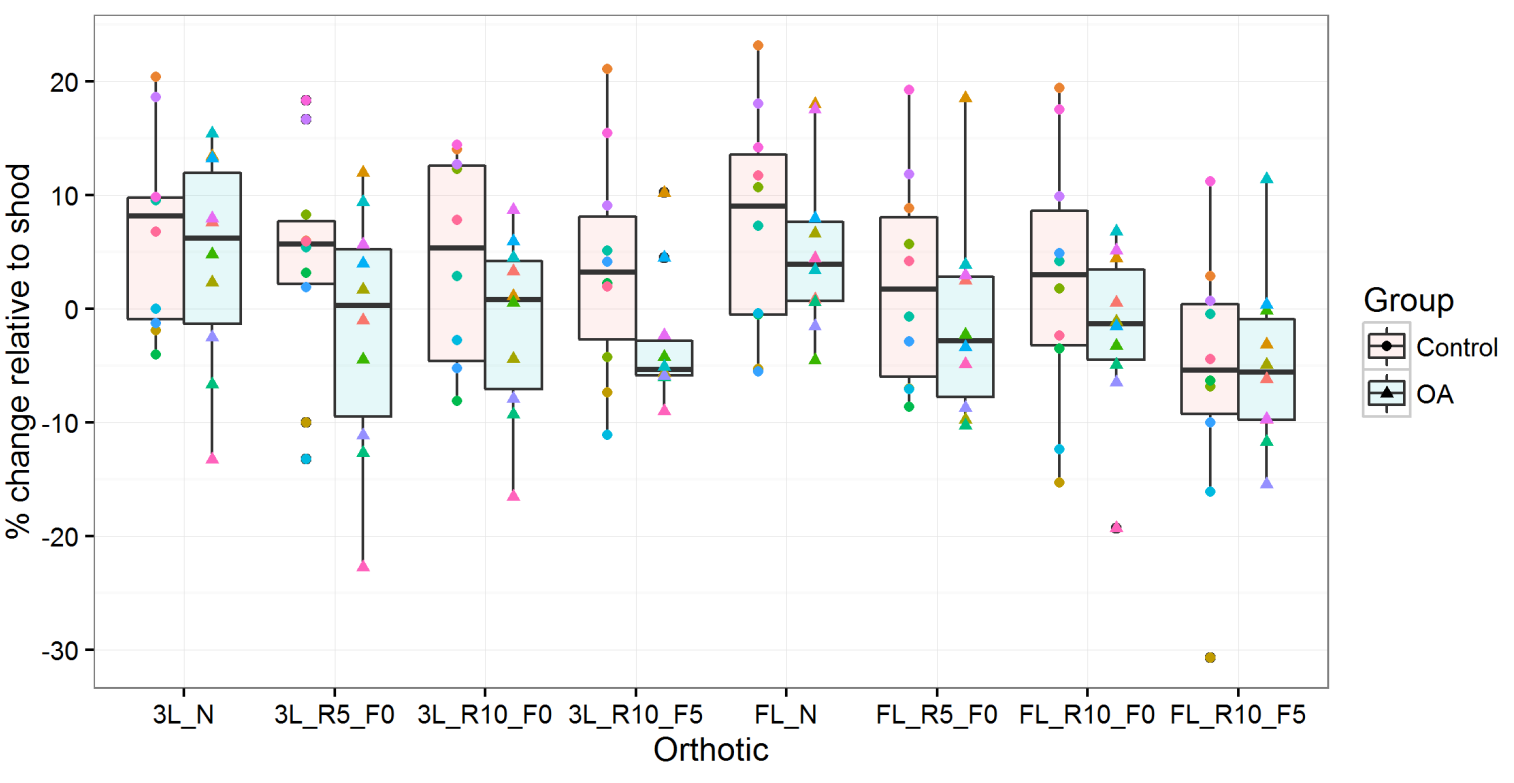

Figure 5 